https://doi.org/10.15421/40280209

Article received $21.03 .2018 \mathrm{p}$.

Article accepted 29.03.2018 p.

удК 582.42.47:069.029:378.4(477.85-25)
ISSN 1994-7836 (print)

ISSN 2519-2477 (online) (c) (1)

$@$ Correspondence author S. G. Litvinenko litvinensv@gmail.com

С. Г. Літвіненко ${ }^{1}$, М. І. Виклюк

${ }^{1}$ Чернівецький національний університет ім. Юрія Федьковича, м. Чернівиі, Украйна ${ }^{2}$ Ботанічний сад Чернівещького національного університету ім. Юрія Федьковича, м. Чернівиі, Украйна

\title{
ВИДОВИЙ СКЛАД ТА СТАН РАРИТЕТНИХ ДЕНДРОЕКЗОТІВ ВІДДІЛУ РІNОРНУТА БОТАНІЧНОГО САДУ ЧЕРНІВЕЦЬКОГО НАЦІОНАЛЬНОГО УНІВЕРСИТЕТУ ІМЕНІ ЮРІЯ ФЕДЬКОВИЧА
}

\begin{abstract}
Наведено результати аналізу видового складу, географічного походження, таксаційних показників, зимостійкості, здатності до генеративного розвитку та розподілу за категоріями раритетності згідно до Червоним списком МСОП деревних інтродуцентів відділу Pinophyta ботанічного саду Чернівецького національного університету ім. Юрія Федьковича. З'ясовано, що в умовах відкритого грунту Саду зростає 39 видів раритетних дендроекзотів відділу Pinophyta із 20 родів, 4 родин. Проведено розподіл за категоріями раритетності відповідно до критеріїв Червоного списку МСОП і показано, що 66,7 \% досліджуваних видів належить до таких, які перебуває під невеликою загрозою (категорія LC). Природоохоронний статус 17,9 \% видів відповідає категоріям CR, EN і VU. За географічним походженням, домінують представники Східної Азії (19 видів) та Північної Америки (14 видів); ендемічними є 51,3\% видів. Установлено, що в умовах Саду всі види зберігають притаманну їм форму росту, при цьому 7 видів досягли характерної для них висоти. Абсолютно зимостійкими в умовах ботанічного саду є 35 видів; формують насіння - 22 види, 3 них розмножуються самосівом 5 видів. Виділено представників, які мають особливу історичну, колекційну і наукову цінність. Подальшому успішному збереженню досліджуваних видів в умовах Передкарпаття сприятимуть вивчення їхньої стійкості до біотичних факторів та з'ясування еколого-ценотичних особливостей.

Ключові слова: дендросозоекзоти відкритого грунту; ботанічний сад; географічне походження; таксаційні параметри; зимостійкість; генеративний розвиток.
\end{abstract}

Вступ. Охорона фіторізноманіття є практично неможливою без збереження таксономічного різноманіття його компонентів, адже зникнення окремих видів чи навіть родів означає незворотну втрату генетичного матеріалу. Ефективним шляхом збереження раритетних видів як аборигенної, так і інтродукованої флори є культивування і розмноження їх в умовах ex situ - у ботанічних садах, дендропарках та інших заповідних парках. Тому впродовж останніх років одним із актуальних напрямів діяльності ботанічних садів і дендропарків України є дендросозологічні дослідження, які охоплюють складання анотованих списків і оцінювання раритетних (тобто тих, що внесені до "червоних списків" та офіційних переліків міжнародного значення, зокрема Червоного списку Міжнародного союзу охорони природи і природних ресурсів (ЧС МСОП), Свропейського Червоного списку, додатків Бернської і Вашингтонської конвенцій) дендроекзотів, культивованих на територіях штучних об'єктів природно-заповідного фонду України, за комплексом показників (Popovych \& Varchenko, 2009). Першим кроком до розроблення науково обгрунтованих заходів збереження та розмноження видів дендросозоекзотів ex situ є інвентаризація їх видового скла- ду та з'ясування природоохоронного статусу (Diachenko, 2011; Kazimirova, 2017; Syplyva, 2014; Stepanenko, 2015). На сьогодні досить детально досліджено дендросозофлору ех situ штучних заповідних об'єктів природно-заповідного фонду Лісостепу України (Diachenko, 2011; Kazimirova, 2017; Kalashnikova \& Halkin, 2017; Medvediev \& Ilienko, 2015; Miskevych, 2016; Stepanenko, 2015). Для штучних заповідних об'єктів Степу України результати інвентаризації та аутосозологічної оцінки дендросозофлори наведено у наукових публікаціях С. Ю. Поповича (Popovych et al., 2013), А. С. Власенко $(2013,2014,2015)$. Таксономічний склад, категоріальну та об'єктну репрезентативність раритетних дендроекзотів Українського Полісся проаналізували Л. Міськевич (2016, 2017) та А. Савоськіна (2016). Тому вважаємо, що інформація про видовий склад та еколого-біологічні особливості дендросозоекзотів штучних заповідних об'єктів природно-заповідного фонду території Передкарпаття матиме вагоме значення для організації ефективної охорони інтродукованого компоненту фітобіоти ex situ на досліджуваній території.

Мета роботи - проаналізувати видовий склад, географічне походження, таксаційні параметри, деякі адап-

\section{Інформація про авторів:}

Літвіненко Світлана Григорівна, канд. біол. наук, доцент кафедри ботаніки, лісового і садово-паркового господарства. Email: litvinensv@gmail.com

Виклюк Марія Ільківна, провідний фахівець відділу рослин відкритого ґрунту. Email: litvinensv@gmail.com

Цитування за ДСтУ: Літвіненко С. Г., Виклюк М. І. Видовий склад та стан раритетних дендроекзотів відділу Ріпорһуta ботанічного саду Чернівецького національного університету імені Юрія Федьковича. Науковий вісник НЛтУ України. 2018, т. 28, № 2. С. 54-58.

Citation APA: Litvinenko, S. G., \& Vykliuk, M. І. (2018). Species Composition and State of Rare Dendroeczotic Plants of Pinophyta in Yuriy Fedkovych Chernivtsi National University Botanical Garden. Scientific Bulletin of UNFU, 28(2), 54-58. https://doi.org/10.15421/40280209 
таційні показники і розподіл за категоріями раритетності дендросозоекзотів відділу Pinophyta, які культивуються у ботанічному саду Чернівецького національного університету ім. Юрія Федьковича (ЧНУ).

Матеріал і методи дослідження. Об'єкт дослідження - раритетні дендроекзоти відділу Pinophyta ботанічного саду ЧНУ, які зростають в умовах відкритого грунту. Таксономічне положення подано згідно з новою міжнародною класифікацією голонасінних (Kuznetsov et al., 2013). Географічний аналіз здійснено відповідно до флористичного районування Землі, яке запропонував А. Л. Тахтаджян (1978). Для созологічного аналізу використано категорії і критерії Червоного списку МСОП (IUCN 2017). Діаметр стовбура вимірювали на висоті 1,3 м за допомогою мірної вилки. Зимостійкість в умовах ботанічного саду ЧНУ оцінювали візуально за 7 бальною шкалою (Lapin \& Sidneva, 1973).

Результати дослідження та їх обговорення. Раритетні дендроекзоти відділу Pinophyta ботанічного саду ЧНУ, які зростають у відкритому грунті, представлені 39 видами із 20 родів, 4 родин. Найчисельнішими за кількістю видів є роди Abies Mill. (6 видів), Picea Dietr. (5 видів), Pinus L. (5 видів). Роди Chamaecyparis Spach, Juniperus L. i Thuja L. містять по 3 види, а до складу решти родів входить по одному виду. У колекції Саду налічується по 1-3 особини того чи іншого виду, і тільки Juniperus sabina зростає куртиною.

У Червоному списку МСОП (IUCN 2017) досліджувані види віднесено до 5 категорій: LC (види під невеликою загрозою або ж викликають найменші побоювання) - 26 видів, NT (близькі до загрозливого стану) - 6, EN (перебувають під загрозою зникнення) - 4, CR (перебувають у критичному стані) - 2, VU (уразливі) 1 вид (табл.). Окрім цього, Pinus koraiensis Siebold \& Zucc. i Taxus cuspidata Sieb. et Zucc. внесено до додатків Конвенції про міжнародну торгівлю видами дикої фауни і флори, яким загрожує зникнення (CITES, Вашингтонська конвенція).

Серед досліджуваних видів $19 €$ вихідцями зі Східної Азії. Природний ареал 14 з них розміщений в межах однієї флористичної області - Східно-Азійської, а природний ареал 4 видів - у межах Східно-Азійської та Циркумбореальної флористичних областей. Представниками північноамериканської дендрофлори є 14 видів. 3 них ареал тільки 6 видів знаходиться в межах однієї флористичної області; решта видів походять з 2-3 флористичних областей. Із Середземноморської флористичної області походить тільки 1 вид, із Циркумбореальної - 2 види. Отже, природний ареал 23 видів досліджуваних дендроекзотів знаходиться у межах однієї флористичної області, ареал 13 видів - у межах двох флористичних областей. Природно зростають на території трьох флористичних областей 3 види (Juniperus sabina L., Pseudotsuga menziesii (Mirb.) Franco, Thuja plicata Donn ex D. Don). Ендемічними є 51,3\% видів: Ginkgo biloba L., Abies cephalonica Loud., A. holophylla Maxim., A. fraseri (Pursh) Poir., A. nordmanniana (Steven) Spach., A. numidica de Lannoy ex Carrière, Picea koyamae Shirasawa, Pinus koraiensis Siebold \& Zucc., Tsuga canadensis (L.) Carrière, Metasequoia glyptostroboides $\mathrm{Hu} \&$ W. C. Cheng, Sequoiadendron giganteum Lindl., Taxodium distichum (L.) Rich., Chamaecyparis lawsoniana (A. Mur- ray bis) Parl., Ch. obtusa (Siebold \& Zucc.) Endl., Ch. pisifera (Sieb. \& Zucc.) Endl., Juniperus virginiana L., Calocedrus decurrens (Torr.) Florin, Microbiota decussata Kom, Thuja standishii (Gordon) Carrière, Thujopsis dolabrata (Thunb. ex L.f.) Siebold \& Zucc. Реліктовими є 3 види - Ginkgo biloba, Taxus cuspidata Sieb. et Zucc., Chamaecyparis obtusa (Takhtadzhyan, 1978). Варто зазначити, що серед ендемічних видів виявилися усі, созологічний статус яких у Червоному списку МСОП відповідає категоріям видів під загрозою (Threatened categories) EN i CR та 4 види категорії NT; серед реліктів - по 1 представнику категорій EN, LC, NT.

За життєвою формою, 29 видів є деревами першої величини, 4 види - деревами другої величини (Abies fraseri, A. numidica, Juniperus chinensis, Platycladus orientalis), 2 види (Picea koyamae, Taxus cuspidata) - деревами третьої величини. Життєва форма кущ характерна для 3 видів: Juniperus sabina, Microbiota decussata, Cephalotaxus fortunei Hook. Притаманної їм у природі висоти досягли в умовах Саду Abies cephalonica, Picea koyamae, Pinus nigra Arn., P. strobus L., Microbiota decussata, Platycladus orientalis, Thuja occidentalis. Дещо нижчими, порівняно із висотою у природному ареалі їхнього зростання, є Abies numidica, Ginkgo biloba, Taxus cuspidata, Taxodium distichum, Chamaecyparis pisifera. Решта представників мають набагато меншу, порівняно із природними розмірами, висоту, оскільки це або молоді рослини (Pinus thunbergii, Tsuga canadensis, Chamaecyparis obtusa), або ж ті, умови культивування яких не задовольняють їхнім екологічним потребам (Abies fraseri, A. holophylla, Picea glauca, P. obovata, Pinus koraiensis, Calocedrus decurrens, Cryptomeria japonica, Cunninghamia lanceolata, Juniperus chinensis, Thujopsis dolabrata, Cephalotaxus fortunei).

Оцінка зимостійкості досліджуваних видів свідчить, що цілком зимостійкими є 35 із них. У Platycladus orientalis, Microbiota decussata, Cryptomeria japonica та Cunninghamia lanceolata в окремі суворі зими підмерзають однорічні пагони (див. табл.), що, однак, не впливає негативно на їх ріст і генеративний розвиток.

Здатність інтродуцентів до генеративного розвитку iз формуванням життєздатного насіння - важлива передумова їхнього успішного розмноження у культурі, що особливо важливо для раритетних дендроекзотів. Оцінка стану генеративного розвитку показала, що в умовах ботанічного саду ЧНУ утворюють насіння 22 види; із них 5 видів розмножуються самосівом: Abies cephalonica, Thuja occidentalis, Th. plicata (види, які мають природоохоронний статус у ЧС МСОП LC), Cryptomeria japonica, Platycladus orientalis (види, природоохоронний статус яких - NT). Утворюють насіння, яке не сходить, 2 види - Sequoiadendron giganteum i Taxodium distichum. Не утворюють насіння Abies concolor, Picea koyamae, P. obovata, Pinus koraiensis, Pseudotsuga menziesii, Metasequoia glyptostroboides, Calocedrus decurrens, Microbiota decussata, Thujopsis dolabrata, а також молоді особини (Tsuga canadensis, Pinus thunbergii) та чоловічі екземпляри (Ginkgo biloba, Cephalotaxus fortunei). Тобто серед 7 видів, віднесених до групи категорій Threatened categories згідно з ЧС МСОП, формує насіння тільки 1 вид; насіння ще 1 виду не сходить; решта представників насіння не формують. 
Табл. Характеристика раритетних дендроекзотів відділу Ріnophyta ботанічного саду ЧНУ

\begin{tabular}{|c|c|c|c|c|c|c|c|c|}
\hline \multirow{2}{*}{$\begin{array}{l}\text { № } \\
\text { 3/ח }\end{array}$} & \multirow{2}{*}{ Вид } & \multirow{2}{*}{$\begin{array}{c}\text { Походження } \\
\text { (флористична } \\
\text { область)* }\end{array}$} & \multirow{2}{*}{$\begin{array}{c}\text { Природоохо- } \\
\text { ронний статус } \\
\text { у ЧС МСОП }\end{array}$} & \multicolumn{2}{|c|}{$\begin{array}{c}\text { Максимальні } \\
\text { значення }\end{array}$} & \multirow{2}{*}{$\begin{array}{l}\text { Вік, } \\
\text { років }\end{array}$} & \multirow{2}{*}{$\begin{array}{c}\text { Кіль- } \\
\text { кість у } \\
\text { колекції }\end{array}$} & \multirow{2}{*}{$\begin{array}{c}\text { Зимос- } \\
\text { тійкість, } \\
\text { бал } \\
\text { (I-VII) } \\
\end{array}$} \\
\hline & & & & висота, м & діаметр, см & & & \\
\hline \multicolumn{9}{|c|}{ Родина Ginkgoaceae L. } \\
\hline 1 & Ginkgo biloba L. ( $\left({ }^{\lambda}\right)$ & Сх.-А3. & \begin{tabular}{|l|}
$\mathrm{EN}$ \\
\end{tabular} & 25 & 107 & понад 140 & 3 & $\mathrm{I}$ \\
\hline \multicolumn{9}{|c|}{ Родина Pinaceae Lindl. } \\
\hline 2 & Abies cephalonica Loud. & Циркумб.+ Середз. & \begin{tabular}{|l|} 
LC \\
\end{tabular} & 28 & 83 & понад 140 & 1 & $\mathrm{I}$ \\
\hline 3 & $\begin{array}{l}\text { A. concolor (Gord.) Lindl.ex Hil- } \\
\text { debr. }\end{array}$ & Скел.гір+ Мадреан. & $\mathrm{LC}$ & 15 & 37 & 30 & 1 & I \\
\hline 4 & A. fraseri (Pursh) Poir. & Атл.-Півн.-Ам. & EN & 3 & 4 & 30 & 1 & I \\
\hline 5 & A. holophylla Maxim. & CX.-A3. & NT & 14 & 26 & 35 & 1 & $\mathrm{I}$ \\
\hline 6 & A. nordmanniana (Steven) Spach & Циркумб. & $\mathrm{LC}$ & 27 & 74 & понад 140 & 1 & $\mathrm{I}$ \\
\hline 7 & $\begin{array}{l}\text { A. numidica de Lannoy ex Car- } \\
\text { rière }\end{array}$ & Середз. & CR & 14 & 29 & 35 & 1 & I \\
\hline 8 & Picea asperata Mast. & Сх.-Аз. & VU & 13 & 33 & 35 & 3 & I \\
\hline 9 & P. glauca (Moench) Voss. & $\begin{array}{c}\text { Циркумб.+ Атл.- } \\
\text { Півн.-Ам. }\end{array}$ & $\mathrm{LC}$ & 15 & 28 & 90 & 1 & I \\
\hline 10 & P. koraiensis Nakai & Циркумб.+ Сх.-Аз. & $\mathrm{LC}$ & 13 & 27 & 35 & 2 & $\mathrm{I}$ \\
\hline 11 & P. koyamae Shirasawa & Сх.-A3. & $\mathrm{CR}$ & 13 & 24 & 50 & 3 & $\mathrm{I}$ \\
\hline 12 & P. obovata Ledeb. & $\begin{array}{l}\text { Циркумб. + Ірано- } \\
\text { Тур. }\end{array}$ & $\mathrm{LC}$ & 4,8 & 9 & 35 & 2 & I \\
\hline 13 & Pinus densiflora Siebold \& Zucc. & Cx.-A3. & $\mathrm{LC}$ & 14 & 37 & 37 & 1 & $\mathrm{I}$ \\
\hline 14 & P. koraiensis Siebold \& Zucc. & Циркумб.+ Сх.-Аз. & $\mathrm{LC}$ & 9 & 17 & 28 & 3 & I \\
\hline 15 & P. nigra Arn. & Циркумб.+ Середз. & $\mathrm{LC}$ & 23 & 55 & понад 140 & 3 & $\mathrm{I}$ \\
\hline 16 & P. strobus L. & $\begin{array}{c}\text { Циркумб.+ Атл.- } \\
\text { Півн.-Ам. }\end{array}$ & $\mathrm{LC}$ & 25 & 74 & понад 140 & 3 & I \\
\hline 17 & P. thunbergii Parl. & CX.-A3. & $\mathrm{LC}$ & 0,4 & - & 12 & 2 & $\mathrm{I}$ \\
\hline 18 & $\begin{array}{l}\text { Pseudotsuga menziesii (Mirb.) } \\
\text { Franco }\end{array}$ & $\begin{array}{l}\text { Мадреан.+Скел. гір } \\
+ \text { Атл.-Півн.-Ам. }\end{array}$ & $\mathrm{LC}$ & 16 & 28 & 45 & 3 & I \\
\hline 19 & Tsuga canadensis (L.) Carrière & $\begin{array}{c}\text { Циркумб.+ Атл.- } \\
\text { Півн.-Ам. } \\
\end{array}$ & NT & 1,3 & - & 12 & 2 & I \\
\hline \multicolumn{9}{|c|}{ Родина Cupressaceae Gray } \\
\hline 20 & $\begin{array}{l}\text { Calocedrus decurrens (Torr.) } \\
\text { Florin }\end{array}$ & Мадреан. & $\mathrm{LC}$ & $9-12$ & 22 & 35 & 2 & I \\
\hline 21 & $\begin{array}{l}\text { Chamaecyparis lawsoniana } \\
\text { (A. Murray bis) Parl. }\end{array}$ & Мадреан. & NT & 25 & 32 & понад 140 & 1 & I \\
\hline 22 & $\begin{array}{l}\text { Ch. obtusa (Siebold \& Zucc.) } \\
\text { Endl. }\end{array}$ & Сх.-Аз. & NT & 15 & 22 & 19 & 2 & I \\
\hline 23 & Ch. pisifera (Sieb. \& Zucc.) Endl. & Cx.-A3. & $\mathrm{LC}$ & 21 & 51 & 110 & 1 & $\mathrm{I}$ \\
\hline 24 & $\begin{array}{l}\text { Cryptomeria japonica (Thunb. } \\
\text { ex L.f.) D. Don }\end{array}$ & Сх.-Аз. & NT & 8 & 21 & 37 & 4 & I (II) \\
\hline 25 & $\begin{array}{l}\text { Cunninghamia lanceolata } \\
\text { (Lamb.) Hook. }\end{array}$ & Сх.-Аз. & $\mathrm{LC}$ & 6 & 23 & 37 & 1 & I-II \\
\hline 26 & Juniperus chinensis L. & Циркумб.+ Сх.-Аз. & $\mathrm{LC}$ & 2,6 & 9 & 80 & 3 & I \\
\hline 27 & J. sabina $\mathrm{L}$. & $\begin{array}{l}\text { Циркумб.+ Середз. + } \\
\text { Ірано-Тур. }\end{array}$ & $\mathrm{LC}$ & 2 & - & 76 & куртина & I \\
\hline 28 & J. virginiana $\mathrm{L}$. & Атл.-Півн.-Ам. & $\mathrm{LC}$ & 14 & 40 & 66 & 1 & $\mathrm{I}$ \\
\hline 29 & $\begin{array}{l}\text { Metasequoia glyptostroboides } \mathrm{Hu} \\
\& \mathrm{~W} \text {. C. Cheng }\end{array}$ & Cx.-A3. & EN & 13 & 13,50 & 30,51 & 2 & I \\
\hline 30 & Microbiota decussata Kom & Циркумб. & $\mathrm{LC}$ & 0,8 & - & 37 & 1 & I (II) \\
\hline 31 & $\begin{array}{l}\text { Platycladus orientalis (L.) Fran- } \\
\text { co }\end{array}$ & Сх.-Аз.+ Ірано-Тур. & NT & 14 & 26 & 65 & 2 & I (II) \\
\hline 32 & $\begin{array}{l}\text { Sequoiadendron giganteum } \\
\text { Lindl. }\end{array}$ & Мадреан. & EN & 25 & 79 & 52 & 1 & I \\
\hline 33 & Taxodium distichum (L.) Rich. & Атл.-Півн.-Ам. & $\mathrm{LC}$ & 25 & 88 & понад 140 & 1 & I \\
\hline 34 & Thuja occidentalis L. & $\begin{array}{c}\text { Циркумб.+ Атл.- } \\
\text { Півн.-Ам. } \\
\end{array}$ & $\mathrm{LC}$ & 26 & 36 & 110 & 1 & I \\
\hline 35 & Th. plicata Donn ex D. Don & $\begin{array}{l}\text { Циркумб.+ Мадре- } \\
\text { ан.+Скел. гір }\end{array}$ & $\mathrm{LC}$ & 27 & 60 & 110 & 1 & I \\
\hline 36 & Th. standishii (Gordon) Carrière & CX.-A3. & $\mathrm{LC}$ & 8,5 & 15 & 33 & 2 & $\mathrm{I}$ \\
\hline 37 & $\begin{array}{l}\text { Thujopsis dolabrata (Thunb. ex } \\
\text { L. f.) Siebold \& Zucc. }\end{array}$ & Сx.-A3. & $\mathrm{LC}$ & 2,6 & 4 & 37 & 2 & I \\
\hline \multicolumn{9}{|c|}{ Родина Taxaceae Gray } \\
\hline 38 & Taxus cuspidata Sieb. et Zucc. & Циркумб.+ Сх.-Аз. & \begin{tabular}{|c|} 
LC \\
\end{tabular} & 5,8 & 14 & 40 & 1 & $\mathrm{I}$ \\
\hline 39 & Cephalotaxus fortunei Hook. (ठ & CX.-A3. & $\mathrm{LC}$ & 2,3 & - & 30 & 2 & $\mathrm{I}$ \\
\hline
\end{tabular}

Примітка: * - подано такі скорочення назв флористичних областей: Атл.-Півн.-Ам. - Атлантично-Північноамериканська; Ірано-Тур. Ірано-Туранська; Мадреан. - Мадреанська; Скел. гір - область Скелястих гір; Сх.-Аз. - Східно-Азійська; Середз. - Середземноморська; Циркумб. - Циркумбореальна. 
У графі "діаметр" знаком (-) позначено види, діаметр стовбура яких не вимірювали (життєва форма їх - кущ, або ж це молоді рослини).

Висновки. Серед раритетних дендроекзотів відділу Pinophyta ботанічного саду ЧНУ домінують види, віднесені у Червоному списку МСOП до категорії LC. Проте особливої охорони потребують реліктові та ендемічні види, зокрема ті, созологічний статус яких у Червоному списку МСОП відповідає категоріям видів, що перебувають під загрозою (Threatened categories) - EN, CR i VU. Висока зимостійкість раритетних видів відділу Pinophyta та здатність до формування насіння 51,3\% iз них є передумовами для подальшого успішного культивування та розмноження цих представників як в умовах ботанічного саду ЧНУ, так і поза його межами. Дендросозоекзоти відділу Pinophyta є цінними не тільки як резерв генетичного матеріалу, але й у науковопізнавальному сенсі. Особливу колекційну, історичну та наукову цінність мають дерева 10 видів, які у Саду досягли віку від 110 до понад 140 років. Досліджувані види мають важливе лісогосподарське і лісомеліоративне значення, є декоративними і придатними для використання в озелененні. Багато видів (Ginkgo biloba, Pinus densiflora, Taxus cuspidata, Juniperus sabina, J. virginiana, Thuja occidentalis) мають лікувальні властивості і використовуються у народній медицині. Для збереження та розмноження досліджуваних видів у культурі в умовах Передкарпаття необхідне подальше з'ясування їхніх еколого-ценотичних особливостей та вивчення стійкості до біотичних факторів.

\section{Перелік використаних джерел}

CITES, Vashington Convention. (2018). Konventsia pro mizhnarodnu torhivliu vydamy dykoi fauny i flory, scho perebuvaiut pid zahrozoiu znyknennia, 23 March 2018. (CITES, Vashynhtonska konventsiia) [Convention on International Trade in Endangered species of Wild Fauna and Flora]. Retrieved from: http://www.cites.org

Diachenko, Ya. M. (2011). Rarytetni dendroekzoty shtuchnykh obliektiv pryrodno-zapovidnoho fondu Lisostepu Ukrainy: reprezentatyvnist i autfitosozolohichnyi konspekt [Rare alien trees in man-made protected objects of the Forest-steppe zone of Ukraine: representativeness and outphytosozological cheklist]. Chornomorskyi botan. zhurn., 7(2), 132-143. [in Ukrainian].

IUCN (2017). The IUCN Red List of Threatened Species. Version 2017-3. Retrieved from: http://www.iucnredlist.org. Downloaded on 05 December 2017.

Kalashnikova, L. V., \& Halkin, S. I. (2017). Taksonomichna struktura sozoflory dendroparku "Oleksandriya" NAN Ukrainy [Taxonomy structure of sozoflora of the dendrological park "Olexandria" of NAS of Ukraine]. Scientific Bulletin of UNFU, 27(3), 38-40. https://doi.org/10.15421/40270307. [in Ukrainian].

Kazimirova, L. P. (2017). Rarytetna dendroflora botanichnoho sadu Khmelnytskoho natsionalnoho universytetu [Rare dendroflora of the Botanical Garden of Khmelnytskyi National University]. Lisove $i$ sadovo-parkove hospodarstvo, 11. Retrieved from: $\mathrm{http} / / /$ nbuv.gov.ua/UJRN/licgoc_2017_11_8. [in Ukrainian].

Kuznetsov, S. I., Kurdiuk, O. V., Maievskyi, K. V., \& Zhyla, K. V. (2013). Taksonomichnyi sklad ta systematyka Holonasinnykh (Pinophyta) dendroflory Ukrainy na osnovi yikh suchasnoi klasyfikatsii [The taxonomic compound and the systematic of Gymnosperms (Pinophyta) of the dendroflora of Ukraine on the basis of their modern classification]. Introdukciia roslyn, 3, 3-11. [in Ukrainian].

Lapin, P. I., \& Sidneva, S. V. (1973). Otcenka perspektivnosti drevesnykh rastenii po dannym vizualnykh nabliudenii. In Opyt intro- duktcii drevesnykh rastenii (pp. 7-67). Moscow: GBS AN SSSR. [in Russian].

Medvediev, V. A., \& Ilienko, O. O. (2015). Rarytetni dendroekzoty viddilu Pinophyta u derzhavnomu dendrolohichnomu parku "Trostianets" NAN Ukrainy [Rarity dendroeczotic plants of Pinophyta in the State Dendrological Park Trostjanets of the NAS of Ukraine]. Introduktsiia roslyn, 3, 78-93. [in Ukraine].

Miskevych, L. (2017). Reprezentatyvnist dendrosozoekzotiv zapovidnykh sadovo-parkovykh ob'iektiv zony shyrokolystianykh lisiv Ukrainy [Representativeness of dendrosozoexotics of the protected landscape gardening objects of the Broadleaf Forests Zone of Ukraine]. Nauk. visnyk Skhidnoievropeiskoho natsionalnoho un-tu. Ser. Biol. nauky, 7, 31-36. [in Ukrainian].

Miskevych, L. V. (2016). Rarytetni vydy derevnykh roslyn Kremenetskoho botanichnoho sadu [Rare species of arboreal plants of Kremenetski Botanical Garden]. Scientific Bulletin of UNFU, 26(5), 98-101. https://doi.org/10.15421/40260514. [in Ukrainian].

Popovych, S. Yu. (Ed.), (2013). Zapovidna dendrosozoflora Stepu Ukrainy. Kyiv: TsP "Komprynt". [in Ukrainian].

Popovych, S. Yu., \& Varchenko, N. M. (2009). Metodyka intehralnoi autfitosozolohichnoi otsinky rarytetnykh dendroekzotiv [Methodology of integral autphytosozological evaluation of rare dendroexotic plants]. Introduktsiia roslyn, 4, 11-17. [in Ukrainian].

Savoskina, A. (2016). Otsiniuvannia dekoratyvnosti dendrosozoekzotiv shtuchnykh zapovidnykh parkiv Ukrainskoho Polissya [Evaluation of decorativeness of dendrosozoekzots of the Ukrainian Polissya]. Nauk. visnyk Skhidnoievropeiskoho natsionalnoho un-tu. Ser. Biol. nauky, 12, 19-23. [in Ukrainian].

Stepanenko, N. P. (2015). Zapovidna ekzotychna dendrosozoflora ex situ Lisostepu Ukrainy (analiz struktury, otsinka dekoratyvnosti, fitodyzain) [Rare exotic dendrosozoflora ex situ of Forest steppe of Ukraine (structure analysis, decorative rating, phytodesign). On the manuscript. Abstract of Doctoral Dissertation for Biology Sciences (06.03.01 - Forest Plantations and Phytomelioration). Kyiv. [in Ukrainian].

Syplyva, N. O. (2010). Strukturnyi analiz rarytetnoi dendroflory parkiv Vinnytskoi oblasti [Structural analysis of rare dendroflora of Vinnitsa Region parks]. Naukovyi visnyk NUBiP Ukrainy. Ser. Lisivnytstvo i dekoratyvne sadivnytstvo, 152(1), 165-169. [in Ukrainian].

Syplyva, N. O. (2014). Inventaryzatsiini doslidzhennia parkivpam'iatok sadovo-parkovoho mystetstva Vinnychyny [Inventory research of parks monuments of landscape art in Vinnitsa Region]. Visnyk natsionalnoho naukovo-pryrodnychoho muzeiu, 12, 116122. [in Ukrainian].

Takhtadzhyan, A. L. (1978). Floristicheskie oblasti Zemli [The floristic regions of the World]. Leningrad: Nauka. [in Russian].

Vlasenko, A. S. (2013). Autfitosozolohichnyi analiz ekzotychnoi dendroflory shtuchnykh parkiv pryrodno-zapovidnoho fondu Stepu Ukrainy [Outphytosozological analysis of exotic dendroflora of man-made parks of the Natural-Reserved Fund of the Steppe of Ukraine]. Scientific Bulletin of UNFU, 23(5), 319-324. Retrieved from: http:/nltu.edu.ua/nv/Archive/2013/23 5/319_Wla.pdf. [in Ukrainian].

Vlasenko, A. S. (2014). Fitotsenotypna struktura zapovidnoi dendrosozoflory ex situ zapovidnykh parkiv Stepu Ukrainy [Phytocenotic structure of reserved dendrosozoflora ex situ of protected parks of Ukraine's Steppe]. Scientific Bulletin of UNFU, 24(9), 118-124. Retrieved from: http://nltu.edu.ua/nv/Archive/2014/24_9/23.pdf. [in Ukrainian].

Vlasenko, A. S. (2015). Reprezentatyvnist kultyvuvannia dendrosozoekzotiv ex situ u shtuchnykh zapovidnykh parkakh Stepu Ukrainy [Analysis of ex situ cultivation rare dendroflora of Ukrainian Steppe]. Biolohichnyi visnyk MDPU, 1, 24-47. https://doi.org/10.7905/bbmspu.v5i1.961. [in Ukrainian]. 
${ }^{1}$ Черновицкий национальный университет им. Юрия Федьковича, г. Черновиыь, Украина ${ }^{2}$ Ботанический сад Черновиџкого национального университета им. Юрия Федьковича, г. Черновиы, Украина

\title{
ВИДОВОЙ СОСТАВ И СОСТОЯНИЕ РАРИТЕТНЫХ ДЕНДРОЭКЗОТОВ ОТДЕЛА PINOРНYТА БОТАНИЧЕСКОГО САДА ЧЕРНОВИЦКОГО НАЦИОНАЛЬНОГО УНИВЕРСИТЕТА ИМЕНИ ЮРИЯ ФЕДЬКОВИЧА
}

\begin{abstract}
Представлены результаты анализа видового состава, географического происхождения, таксационных показателей, зимостойкости, генеративного развития и распределения по категориям раритетности (в соответствии с Красным списком MCOП) древесных интродуцентов отдела Pinophyta ботанического сада Черновицкого национального университета им. Юрия Федьковича. Выяснено, что в условиях открытого грунта Сада произрастает 39 видов раритетных дендроэкзотов отдела Pinophyta, относящихся к 20 родам, 4 семействам. Произведено распределение по категориям раритетности в соответствии с критериями Красного списка МСОП и показано, что 66,7 \% исследуемых видов относятся к таким, которые находятся под небольшой угрозой исчезновения (категория LC). Природоохранный статус 17,9\% видов соответствует категориям CR, EN, VU. По географическому происхождению, доминируют представители Восточной Азии (19 видов) и Северной Америки (14 видов); эндемиками являются 51,3\% видов. Показано, что в условиях Сада все виды сохраняют характерную для них форму роста, при этом 7 видов достигают свойственных им размеров. Выяснено, что вполне зимостойкими в условиях ботанического сада являются 35 видов; формируют семена - 22 вида, из них 5 видов размножаются самосевом. Выделены растения, имеющие особенную историческую, коллекционную и научную ценность. Дальнейшему успешному сохранению исследуемых видов в условиях Прикарпатья будет способствовать изучение их устойчивости к биотическим факторам и исследование их эколого-ценотических особенностей.
\end{abstract}

Ключевые слова: дендросозоэкзоты открытого грунта; ботанический сад; географическое происхождение; таксационные показатели; зимостойкость; генеративное развитие.

S. G. Litvinenko' ${ }^{1}$, M. I. Vykliuk ${ }^{2}$

${ }^{1}$ Yuriy Fedkovych Chernivtsi National University, Chernivtsi, Ukraine

${ }^{2}$ Botanical Garden of Yuriy Fedkovych Chernivtsi National University, Chernivtsi, Ukraine

\section{SPECIES COMPOSITION AND STATE OF RARE DENDROECZOTIC PLANTS OF PINOPHYTA IN YURIY FEDKOVYCH CHERNIVTSI NATIONAL UNIVERSITY BOTANICAL GARDEN}

An effective direction of rare exotic plant species preservation is their ex situ cultivation conditions that is realized for introduced plants in botanical gardens, dendrological parks and other preserved parks. Lately, first actions for preservation rare woody plants in ex situ conditions in Ukraine are inventory research, elucidation of their spreading in cultivated area, their conservation status due to the Red Lists of international significance (such as The IUCN Red List of Threatened Species) and estimation of their adaptation level. Therefore, the purpose of our research is to analyze species composition, conservation status due to The IUCN Red List of Threatened Species, geographical origin, taxation parameters, winter resistance and generative development of Pinophyta rare woody exotic plants cultivated in Chernivtsi National University Botanical Garden. At the beginning of 2018, 39 species of rare dendroexotic plants of Pinophyta are growing in the open ground conditions in Botanical Garden. They belong to 20 genus, 4 families. The authors have ascertained that 19 species originated in East Asia and 14 species are from North America. $51.3 \%$ of species are endemics and 3 species are relicts. All species are recorded in The Red List of Threatened Species and are distributed by 5 categories; species from LC category are predominated (26 species). According to The IUCN Red List, all species that belong to EN (Endangered) and CR (Critically Endangered) categories and 4 species of NT (Near Threatened) category are endemics, so they need special conservation actions. 33 species are trees ( 29 among them are trees of first magnitude) and 3 species are shrubs. All species retain the growth form, while 7 species have reached the typical height for them. 35 species are revealed to be completely winter-hardly. 22 species form seeds and 5 species are self-propagated. Thus, Pinophyta rare woody exotic plants of Chernivtsi National University Botanical Garden are valuable as a reserve of genetic material and plants in the scientific and educational meaning. Trees of 10 species that have a special historical, collectible and scientific value are pointed out; they are from 110 to above 140 years old. Investigated plants have also forestry, meliorative, decorative and medicinal value. Further successful preservation of these species in the Pre-Carpathian region will be possible if their resistance to biotic factors, ecological and coenotic peculiarities is studied.

Keywords: dendrosozoeczotics of open ground area; botanical garden; geographical origin; taxation parameters; winter resistance; generative development. 